\title{
Synthesis of graphene using gamma radiations
}

\author{
LEILA SHAHRIARY and ANJALI A ATHAWALE* \\ Department of Chemistry, University of Pune, Pune 411 007, India
}

MS received 8 February 2014; revised 2 September 2014

\begin{abstract}
Considering the advantages of radiolytic synthesis such as the absence of toxic chemical as a reducing agent, uniform distribution of reducing agent and high purity of product, the synthesis of graphene (rGO) from graphene oxide (GO) by the gamma irradiation technique using a relatively low dose rate of $0.24 \mathrm{kGy} \mathrm{h}^{-1} \mathrm{has}$ been described. Structural and physicochemical properties of GO and rGO were investigated with the help of various characterization techniques. The presence of peak at $271 \mathrm{~nm}$ in ultraviolet-visible spectrum, $\mathrm{C}=\mathrm{C}$ aromatic stretching vibrations between 1450 and $1600 \mathrm{~cm}^{-1}$ in the Fourier transform infrared spectrum and significant decrease in photoluminescence peak intensity at 470 and $567 \mathrm{~nm}$ wavelengths represent the reduction of GO to graphene by gamma irradiation. The decrease in stacking height from $7.71 \mathrm{~nm}$ in GO to $3.52 \mathrm{~nm}$ in rGO as observed from the $\mathrm{X}$-ray powder diffraction analysis further confirms the same. Raman spectra show significantly lower $D$ to $G$ band ratio for rGO compared with GO. Also, the cyclic voltammograms obtained using GO- and rGO-modified electrodes (working electrode) in standard redox system show enhanced peak intensities together with decrease in potential difference between oxidation and reduction peaks in case of graphene.
\end{abstract}

Keywords. Graphene oxide; gamma radiations; reduction; graphene.

\section{Introduction}

Graphene is a two-dimensional single layer of carbon arranged in a honeycomb network. It received incredible attention in diverse areas of research because of its extraordinary electrical and thermal conductivities, ${ }^{1,2}$ high mechanical strength, ${ }^{3}$ large specific surface area, good biocompatibility and low manufacturing cost. ${ }^{4}$ The high electrical and thermal conductivities of graphene originate from the extended long-range $\pi$-conjugation. The biocompatibility, high conductivity and the large surface area of graphene have made it an ideal candidate in the development of bioelectronic devices. The outstanding properties of graphene have been a subject in the development of ultrafast electronic and optical devices, energy storage, photo-catalysis, electrochemical sensors and biosensors. ${ }^{5-10}$ Research has been focused to a large extent on developing routes to obtain large sheets of monolayer or bi-layer graphene. Graphene was initially isolated by mechanical exfoliation, peeling off the top surface of small mesas of pyrolytic graphite, ${ }^{11,12}$ which is not appropriate for largescale applications. At later stages, single sheets of graphene oxide (GO) were chemically reduced to graphene (rGO) after deposition on a silicon substrate; ${ }^{13,14}$ this method also has limited applications. In recent times, large sheets of graphene have been synthesized by chemical vapour deposition (CVD) of $\mathrm{CH}_{4}$ or $\mathrm{C}_{2} \mathrm{H}_{2}$ gases on copper or nickel substrates. ${ }^{15,16}$ However, the CVD method also

\footnotetext{
*Author for correspondence (agbed@ chem.unipune.ac.in)
}

involves limitations due to the use of gaseous raw materials. Another approach to synthesize GO in bulk is exfoliation of graphite oxidized with strong acids either by rapid thermal expansion ${ }^{17}$ or by ultrasonic dispersion. ${ }^{18,19}$ However, these methods yield graphene sheets with higher degree of defects. Numerous reducing agents including hydrazine, ${ }^{20}$ sodium borohydride $^{21}$ and hydroquinone ${ }^{22}$ have been used for the chemical reduction of GO. However, they are highly poisonous, explosive and cause more defects on graphene sheets. ${ }^{20}$ Thus, a novel route to synthesize graphene is still a challenge.

Gamma $(\gamma)$-rays are electromagnetic radiations with high energy and short wavelength. For the past two decades, the use of $\gamma$-radiations in the preparation of colloidal metal nanoparticles, composites and in the studies of redox processes occurring on these particles has been found to be highly advantageous. ${ }^{23-25}$ Important advantages of $\gamma$-ray synthesis compared with other methods such as chemical are: (1) reduction can be carried out without using excess reducing agent or producing undesired oxidation products of the reductant, (2) the reducing agent is uniformly generated in the solution, (3) radiation is absorbed regardless of the presence of light-absorbing solutes and products, (4) simplicity and (5) cost effective. Also, in radiolytic method it is easier to control the size, shape and size distribution of nanoparticles by optimizing parameters such as dose and dose rate. The results of $\gamma$-irradiation reaction strongly depend on irradiation conditions, the material type and irradiation medium. ${ }^{26-29}$ The dose rate has significant effect on the above-mentioned features of the product. ${ }^{30}$ It has been reported that the interaction between the $\gamma$-radiations and 
the multi-walled carbon nanotubes with the absorbed dose of $150 \mathrm{kGy}$ destroyed the nanostructure of carbons, leading to the formation of diamond-like structures and carbon oxides. In addition, $\gamma$-irradiation with an absorbed dose of 100 $\mathrm{kGy}$ improved graphitization and surface properties of multiwalled carbon nanotubes while at higher absorbed dose (150 $\mathrm{kGy}$ ), it resulted in damaged structures. ${ }^{27}$ Zhang et $a l^{28,29}$ have reported for the first time the synthesis of graphene using a dose rate of $0.88 \mathrm{kGy} \mathrm{h}^{-1}$ and a total absorbed dose of $35.3 \mathrm{kGy}$. In addition, the effect of $\gamma$-irradiation at a higher dose rate of $3 \mathrm{kGy} \mathrm{h}^{-1}$ and absorbed dose of 60$150 \mathrm{kGy}$ on graphene with few layers have been investigated recently. ${ }^{26}$

In the present paper, attempts were made to check the feasibility of formation of graphene (rGO) using a relatively low dose rate of $0.24 \mathrm{kGy} \mathrm{h}^{-1}$ for a total absorbed dose between 2.88 and $14.40 \mathrm{kGy}$. The analysis of the products revealed that complete reduction of GO to rGO occurs at a total dose of $11.52 \mathrm{kGy}$ by irradiating the solution of GO in 1:1 water-alcohol mixture which is significantly lower than previous reports. A comparison between our results with those of others ${ }^{26,28,29}$ reveals that reduction of GO occurs at a lower dose rate as well as lower absorbed dose. Also, the electrocatalytic activity of samples before and after irradiation has been investigated. The electrochemical analysis indicates an enhancement in the electrocatalytic activity of rGO.

\section{Experimental}

\subsection{Chemicals and reagents}

Graphite powder, $\mathrm{H}_{2} \mathrm{SO}_{4}, \mathrm{NaNO}_{3}, \mathrm{NaOH}, \mathrm{H}_{2} \mathrm{O}_{2}(30 \%), \mathrm{K}_{3} \mathrm{Fe}$ $(\mathrm{CN})_{6}$ and $\mathrm{KMnO}_{4}$ were purchased from Sigma-Aldrich (USA). Methanol, ethanol, isopropanol and tert-butanol were obtained from SD-Fine Chemical (SDFCL, India). All the chemicals were of analytical reagent grades and used as received, without further purifications. The aqueous solutions were prepared in Milli-Q water $\left(18 \mathrm{M} \Omega \mathrm{cm}^{-1}\right)$.

\subsection{Instrumentation}

The ${ }^{60} \mathrm{Co} \gamma$-source was from the Department of Chemistry, University of Pune, supplied by BARC (Bhabha Atomic Research Center), Mumbai, India, with a dose rate of 0.24 $\mathrm{kGy} \mathrm{h}^{-1}$. The solutions were sonicated using an IMECO $34 \mathrm{KHz}$ frequency, $500 \mathrm{~W}$ sonicator. The cyclic voltammetric (CV) measurements were performed on CHI 1100 Electrochemical Analyzer using a conventional three-electrode system. All the electrochemical measurements were carried out in an air-tight borosilicate jacket glass cell with B-14 standard glass joints to fix the electrodes. The electrochemical cell consisted of a glassy carbon (GC) electrode $(3 \mathrm{~mm}$ diameter) modified with $\mathrm{GO}$ and $\mathrm{rGO}$ as working electrode, $\mathrm{Ag} / \mathrm{AgCl} / \mathrm{sat}$. $\mathrm{KCl}$ as a reference electrode and $\mathrm{Pt}$ as a counter electrode. For measurement of resistance, pellets of the samples $\left(1 \mathrm{~cm}^{2}\right.$ and $500 \mu \mathrm{m}$ in thickness) were prepared by placing $50 \mathrm{mg}$ of each powder between two iron plates of a die and compressed at a pressure of $78 \mathrm{kN}$.

\subsection{Synthesis of $G O$}

GO was synthesized from graphite powder using modified Hummer's method. ${ }^{31}$ In brief, $1 \mathrm{~g}$ of graphite and $0.5 \mathrm{~g}$ of sodium nitrate were mixed together followed by the addition of $23 \mathrm{ml}$ of conc. sulphuric acid under constant stirring. After $1 \mathrm{~h}, 3 \mathrm{~g}$ of $\mathrm{KMnO}_{4}$ was added gradually to the above solution while keeping the temperature less than $20^{\circ} \mathrm{C}$ to prevent overheating and explosion. The mixture was stirred at $35^{\circ} \mathrm{C}$ for $1 \mathrm{~h}$ and the resulting solution was diluted by adding 500 $\mathrm{ml}$ of water under vigorous stirring. To ensure the completion of reaction with $\mathrm{KMnO}_{4}$, the suspension was further treated with $30 \% \mathrm{H}_{2} \mathrm{O}_{2}$ solution $(5 \mathrm{ml})$. The resulting mixture was washed with $\mathrm{HCl}$ and $\mathrm{H}_{2} \mathrm{O}$ followed by filtration and drying, the GO sheets were thus obtained.

\subsection{Synthesis of graphene ( $r G O)$}

GO (5 mg) was dispersed in $10 \mathrm{ml}$ of ethanol-water $(1: 1)$ mixture using ultrasonic bath for $30 \mathrm{~min}$. The dispersion was transferred into a glass bottle fitted with a septum. The dissolved oxygen was removed by bubbling nitrogen gas for $10 \mathrm{~min}$. The samples were irradiated in a ${ }^{60} \mathrm{Co} \gamma$-ray source at a dose rate of $0.24 \mathrm{kGy} \mathrm{h}^{-1}$ for different doses (2.88$14.40 \mathrm{kGy}$ ). The product so obtained was collected and washed with Milli-Q water and dried under vacuum. Similar procedure was adopted for other alcohols.

\subsection{Preparation of electrodes}

GC electrode (3.0 mm diameter) was polished with alumina nano-powder and rinsed with Milli-Q water. Fresh dispersion of samples ( $\mathrm{GO}$ and $\mathrm{rGO}$ ) were prepared for each experiment by dispersing $1.0 \mathrm{mg}$ of each sample in $1.0 \mathrm{ml}$ of Milli-Q water with sonication. From this, $10 \mu \mathrm{l}$ of solution was drop-casted on the pre-cleaned GC disk electrode and dried under vacuum at room temperature. Bare GC and GC modified with GO and rGO were used for the electrochemical measurements.

\subsection{Characterization techniques}

Fourier transform infrared (FTIR) spectra of the samples were recorded on a Thermo Scientific NICOLET 6700 spectrophotometer using $\mathrm{KBr}$ as the mulling agent. UltravioletVisible (UV-Vis) spectra of the samples were collected on a UV-Vis spectrophotometer (Perkin-Elmer LAMBDA 950). Photoluminescence (PL) spectra of the samples were recorded on a spectrofluorometer (JASCO, FP8300) and $\mathrm{X}$-ray diffraction (XRD) analysis of powders were carried out on Bruker AXSD-8 Advance X-ray diffractometer with monochromatic $\mathrm{CuK} \alpha$, radiation $(\lambda=1.5406 \AA)$. Data were collected from $10^{\circ}$ to $60^{\circ}$ at a scan rate of $0.1^{\circ} \mathrm{min}^{-1}$. The morphologies of the samples were observed under scanning electron microscope (SEM, JEOL JSM-6360). Raman spectra of the samples were recorded by Horiba JobinYvon, 
France at $\lambda=532 \mathrm{~nm}$ laser power $1.7 \mathrm{~mW}, 100 \times$ objective lens, 0.9 NA.

\section{Results and discussion}

Graphene was synthesized by $\gamma$-irradiation of dispersion of GO powder in $1: 1(\mathrm{~V} / \mathrm{V})$ ethanol-water mixture by irradiating the samples for different doses between 2.88 and 14.40 $\mathrm{kGy}$ at a dose rate of $0.24 \mathrm{kGy} \mathrm{h}^{-1}$. Preliminary investigations were carried out by recording the UV-Vis spectra of irradiated samples. Figure 1 shows the UV-Vis spectra of the samples obtained after irradiation along with un-irradiated GO dispersion. From the figure, it is observed that GO shows maximum absorption peak at $\sim 237 \mathrm{~nm}$ attributable to $\pi-\pi^{*}$ transition of the atomic $\mathrm{C}-\mathrm{C}$ bonds and shoulder peak at $\sim 300 \mathrm{~nm}$ due to $\mathrm{n}-\pi *$ transitions of aromatic $\mathrm{C}-\mathrm{C}$ bonds. ${ }^{28,29,32,33}$ Similar spectrum was obtained for sample after irradiation for $2.88 \mathrm{kGy}$. However, after irradiation for a dose of $5.76 \mathrm{kGy}$ the spectrum shows a decrease in the intensity of peak as well as a shoulder corresponding to GO along with a red shift in the peak of $\sim 4 \mathrm{~nm}$ (237$241 \mathrm{~nm}$ ), indicating partial reduction of GO to graphene. An additional peak observed in $\mathrm{rGO}$ at $\sim 208 \mathrm{~nm}$ represents the absorbance due to the formation of $\mathrm{C}-\mathrm{H}$ bonds during reduction simultaneous to $\mathrm{C}-\mathrm{C}$ bond breaking. ${ }^{34}$ Further irradiation of sample to a dose of $11.52 \mathrm{kGy}$ shows a sharp decrease in the absorbance with a drastic red shift in the peak from 237 to $271 \mathrm{~nm}$ which can be attributed to complete reduction of $\mathrm{GO}$ to $\mathrm{rGO}$, and the restoration of $\mathrm{C}=\mathrm{C}$ bonds, ${ }^{28,29}$ the decrease in the intensity of absorbance additionally indicates the complete reduction since rGO has lower solubility compared with GO. The red shift is related to the enhanced electron concentration and structural ordering, thereby confirming the restoration of $\mathrm{sp}^{2}$ carbon atoms and formation of graphene with better quality. The spectrum of the sample irradiated for a dose of $14.40 \mathrm{kGy}$ shows an overlap with

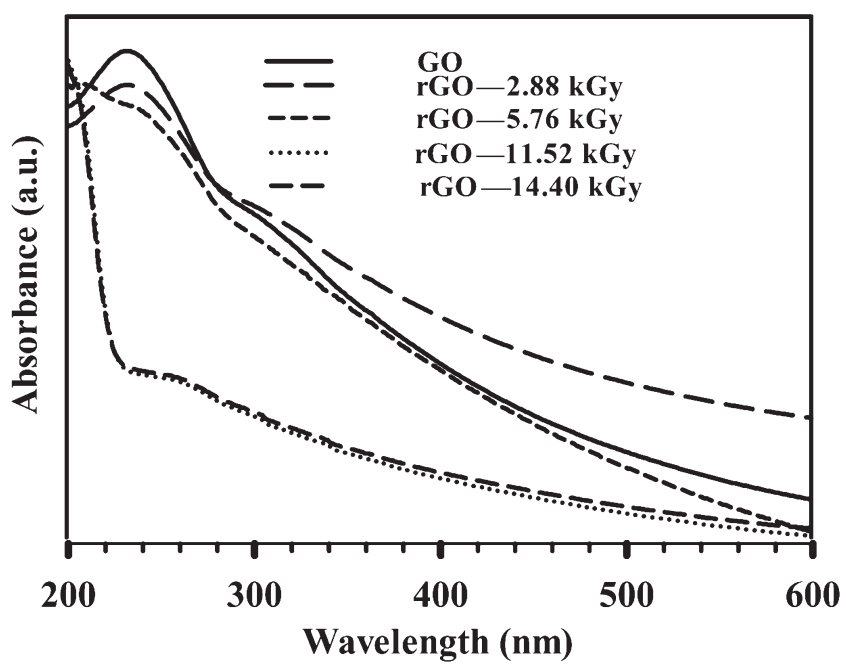

Figure 1. UV-Vis spectra of un-irradiated GO and rGO obtained after irradiation of GO $+1: 1$ water-ethanol solutions for different gamma doses. the spectrum obtained after $11.52 \mathrm{kGy}$ indicating saturation. These results led us to conclude that $11.52 \mathrm{kGy}$ is an optimum dose for efficient conversion of GO to rGO. Therefore, further analyses were carried out for the sample irradiated for a dose of $11.52 \mathrm{kGy}$.

Water on $\gamma$-irradiation is known to undergo radiolysis (decomposition) forming both, oxidative as well as reductive species. When alcohol is added to water, it scavenges the $\mathrm{OH}$ radicals, forming water together with alcohol radicals. ${ }^{35-37}$ These alcohol radicals provide a reducing medium for chemical reaction to occur under $\gamma$-irradiation in the absence of oxygen (oxygen supports formation of strong oxidative products such as $\mathrm{H}_{2} \mathrm{O}_{2}, \mathrm{O}_{2} \mathrm{H}$ and $\mathrm{O}_{2}^{-}$)

$$
\begin{aligned}
& \mathrm{H}_{2} \mathrm{O} \stackrel{\gamma \text {-irradiation }}{\longrightarrow} \mathrm{e}_{\text {eq }}^{-}+\mathrm{H}^{-}+\mathrm{OH}, \\
& \mathrm{RH}+\mathrm{OH}(\mathrm{H}) \rightarrow \mathrm{H}_{2} \mathrm{O}\left(\mathrm{H}_{2}\right)+\mathrm{R},
\end{aligned}
$$

where RH corresponds to methanol, ethanol, isopropanol and tert-butanol. The effect of different alcohol radicals was investigated by irradiating the dispersion of GO in a series of $1: 1$ (V/V) water-alcohol (methanol, ethanol, isopropanol and tert-butanol) mixtures. The UV-Vis spectra of the samples are shown in figure 2. As noted from the figure, the maxima of the absorption peak for rGO appears at 245 , 240, 260 and $271 \mathrm{~nm}$ for methanol, tert-butanol, isopropanol and ethanol, respectively. These results imply that ethanolwater system serves as the best medium, resulting in efficient conversion of GO to rGO. This can be attributed to the differences in the rate constants of alcohols for scavenging hydroxyl radicals where ethanol exhibits the highest rate constant compared with other alcohols as reported by Janata, ${ }^{38}$ for aqueous solutions of water and alcohols by pulse radiolysis. The FTIR spectra for GO and irradiated sample are depicted in figure 3. The FTIR spectrum of GO represents

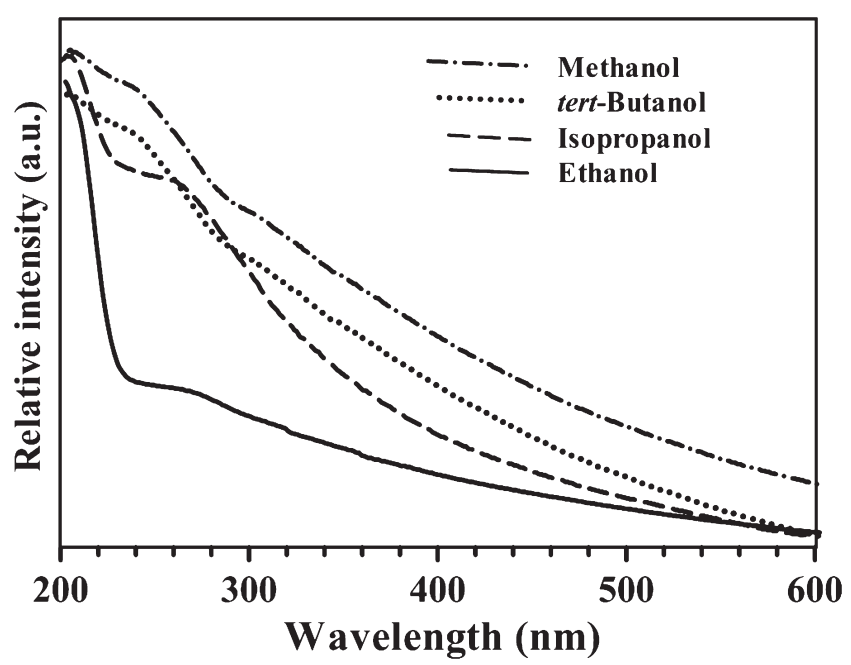

Figure 2. UV-Vis spectra of rGO obtained after irradiation of $\mathrm{GO}+1: 1$ water-alcohol mixtures for a total dose of $11.52 \mathrm{kGy}$. 
two peaks at $\sim 1630$ and $\sim 1740 \mathrm{~cm}^{-1}$ attributable to $\mathrm{C}=\mathrm{C}$ and $\mathrm{C}=\mathrm{O}$ stretching vibrations, respectively, and a broad peak at $\sim 3300 \mathrm{~cm}^{-1}$ can be assigned to stretching mode of $\mathrm{O}-\mathrm{H}$ bond. ${ }^{39}$ In contrast with this, disappearance of all the above-mentioned peaks simultaneous to the appearance of two new peaks between 1450 and $1600 \mathrm{~cm}^{-1}$ associated with the $\mathrm{C}=\mathrm{C}$ of aromatic ring confirms the reduction of functional groups of $\mathrm{GO}$ and formation of graphene (figure 3).

The PL spectra of GO and $\mathrm{rGO}$ were recorded using an excitation wavelength of $240 \mathrm{~nm}$ as shown in figure 4. The emission peak at $307 \mathrm{~nm}$ is due to oxidation of graphite and formation of crystalline graphitic $\mathrm{sp}^{2}$ in GO. Additionally, a strong peak at $\sim 470 \mathrm{~nm}$ is attributable to the $\pi-\pi^{*}$ transitions of GO. The remarkable sharp emission peak at $\sim 567$ $\mathrm{nm}$ (visible range) in $\mathrm{GO}$ arise due to the $\mathrm{CO}, \mathrm{C}=\mathrm{O}$ and $\mathrm{O}=\mathrm{C}-\mathrm{OH}$ functionalized groups present on the GO. Contrary to this, significant decrease in the intensity of the PL

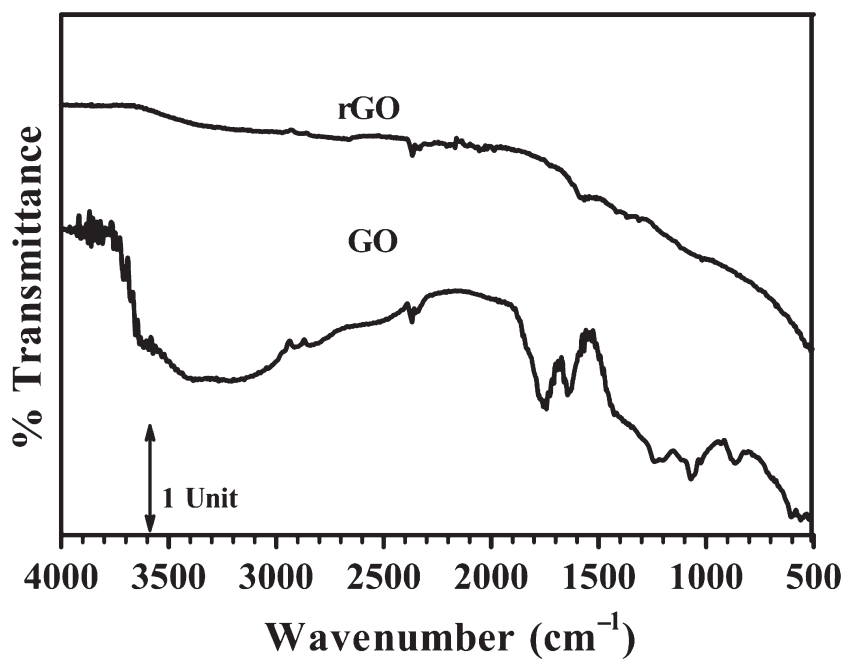

Figure 3. FTIR spectra of GO and rGO (from bottom to top).

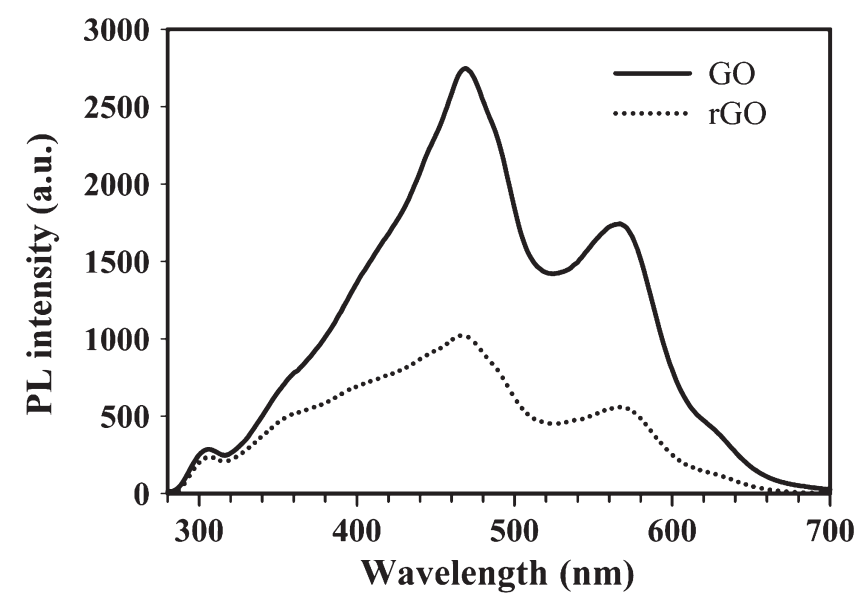

Figure 4. PL spectra of GO (solid line) and rGO (dotted line) obtained at an excitation wavelength of $240 \mathrm{~nm}$. spectrum in case of irradiated sample correspond to quenching of PL due to removal of functional groups and restoration of greater number of $\mathrm{sp}^{2}$ clusters, further confirming the formation of $\mathrm{rGO} .{ }^{40}$

The morphologies of the samples could be observed with the help of SEM analysis (figure 5). The SEM images of GO (figure 5a and b) show randomly aggregated wrinkled sheets associated with each other, while, the SEM images of graphene (figure 5c and d) exhibit thinner, wrinkled sheets and fluffy structure.

The X-ray diffractograms of GO and $\mathrm{rGO}$ (figure 6), reveal the presence of graphitic peaks at $2 \theta=12.05^{\circ}$ for $\mathrm{GO}$ and $2 \theta=25.88^{\circ}$ for rGO. The $d$-spacing ${ }^{41}$ were calculated by Bragg's law (3) and are found to be $7.27 \AA$ for GO and 3.44 $\AA$ for rGO. ${ }^{42}$

$$
\lambda=2 d \sin \theta,
$$

where $\lambda$ is the wavelength of the X-ray beam $(0.154 \mathrm{~nm}), d$ the distance between the adjacent GO sheets or layers and $\theta$ the diffraction angle. ${ }^{41}$

The thickness of crystallites (stacking heights) computed by Debye-Scherrer equation (4) for GO, and $\mathrm{rGO}$ are found to be 7.71 and $3.52 \mathrm{~nm}$, respectively.

$$
l_{\mathrm{a}}=\frac{0.89 \lambda}{\beta \cos \theta},
$$

where $l_{\mathrm{a}}$ is the stacking height, 0.89 is a constant dependent on the crystallite shape, $\lambda$ the X-ray wavelength, $\beta$ and $\theta$ the full-width at half-maxima (FWHM). ${ }^{43-45}$ The variation in stacking height between $\mathrm{GO}$ and $\mathrm{rGO}$ reflects the influence of irradiation on the structure as well as morphology of the GO.

In addition, the reduction of GO to $\mathrm{rGO}$ has also been verified by Raman spectroscopy. This characterization gives useful information related to the electronic and structural properties of graphene. The representative Raman peaks of graphene are reported to be as D $\left(\sim 1348 \mathrm{~cm}^{-1}\right), \mathrm{G}(\sim 1592$ $\left.\mathrm{cm}^{-1}\right)$ and 2D $\left(\sim 2704 \mathrm{~cm}^{-1}\right)$ bands. The $\mathrm{G}$ band represents the $E_{2 g}$ mode that is in-plane optical vibration of aromatic carbon rings and depicts the relative degree of graphitization. The $\mathrm{D}$ band corresponds to the degree of disorder and its intensity shows the level of edge chirality. Therefore, the intensity ratio of $\mathrm{G}$ : D bands of rGO represents the various types of disorders such as defects, ripples and edges. ${ }^{46,47}$ Figure 7 shows the Raman spectra of GO and rGO samples. The $I_{\mathrm{D}} / I_{\mathrm{G}}$ and $I_{2 \mathrm{D}} / I_{\mathrm{D}+\mathrm{G}}$ ratio of GO (1.02 and 1.32) are remarkably lower than that of $\mathrm{rGO}$ (1.24 and 1.50), respectively, indicating less topological disorder, defect density and higher degree of crystallinity in the rGO structure. ${ }^{42}$ Also, the widths of $\mathrm{D}$ and $2 \mathrm{D}$ peaks for $\mathrm{GO}$ are greater compared with that of rGO. ${ }^{46,47}$ These results indicate that rGO has more perfect conjugated structure that leads to enhanced electron transfer.

The electrochemical properties of the samples were studied with reference to $\mathrm{K}_{3} \mathrm{Fe}(\mathrm{CN})_{6}$ redox system because of its sensitivity to the surface chemistry and microstructure 

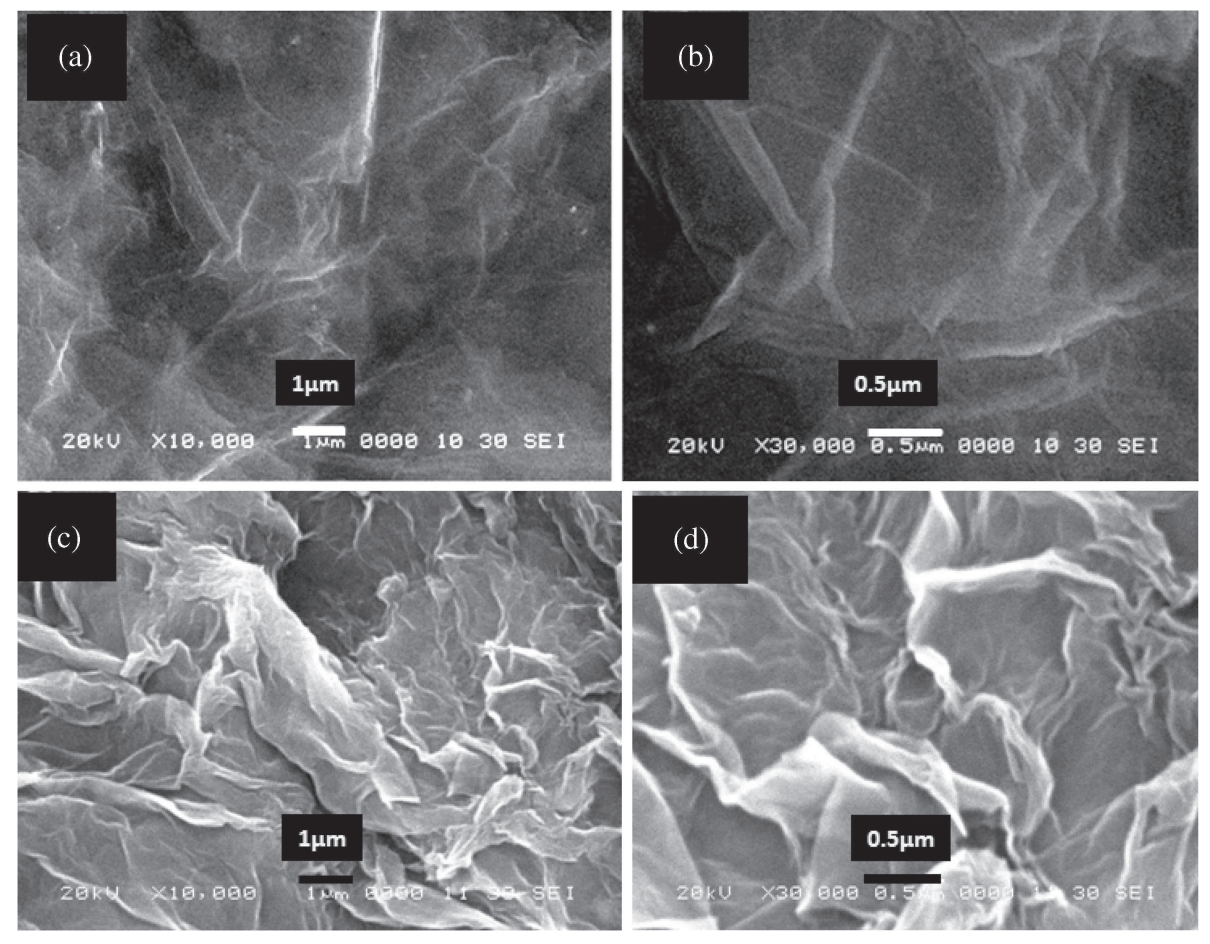

Figure 5. SEM micrographs of (a and b) GO and (c and d) rGO samples.

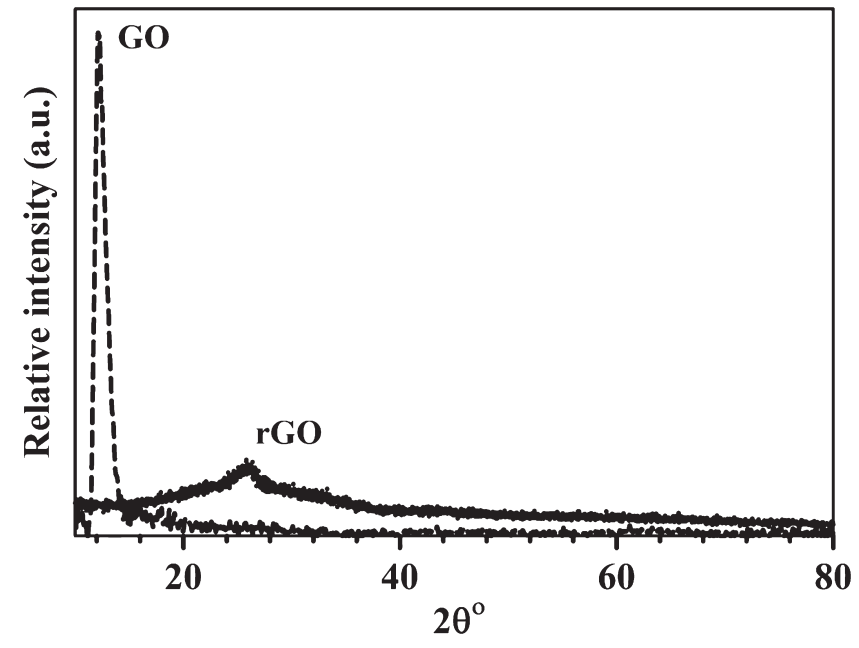

Figure 6. X-ray diffractograms of $\mathrm{GO}$ and $\mathrm{rGO}$ samples.

as well as the density of electronic states near the Fermi potential. ${ }^{48}$ Figure 8a shows the electrochemical response of $\mathrm{K}_{3} \mathrm{Fe}(\mathrm{CN})_{6}[5 \mathrm{mM}], \mathrm{KCl}[0.5 \mathrm{mM}]$ at bare GC-, GO- and rGO-modified electrodes at a scan rate of $100 \mathrm{mV} \mathrm{s}^{-1}$. The cyclic voltammogram of $\mathrm{K}_{3} \mathrm{Fe}(\mathrm{CN})_{6}$ is apparently enhanced at rGO-modified electrode (solid line) compared with GO (dashed line), as reflected by the increase in the peak current $\left(I_{\mathrm{p}}\right)$ together with decrease in the peak to peak potential $\left[\Delta E_{\mathrm{p}}=0.11\right.$ for $\mathrm{rGO}$ and $\Delta E_{\mathrm{p}}=0.15$ for GO]. The peak currents are observed to increase linearly as a function of square root of the scan rate $\left(50-500 \mathrm{mV} \mathrm{s}^{-1}\right)$, for both, GO and rGO (figure $8 \mathrm{~b}$ and c). This indicates that the

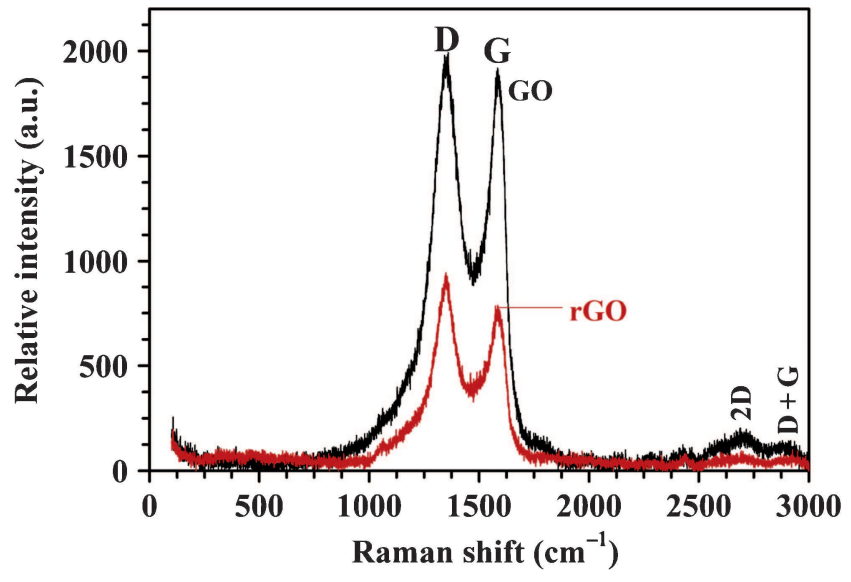

Figure 7. Raman spectra of GO and rGO (top to bottom).

electrochemical reaction occurring at the electrode surface is diffusion controlled. The linear regression equation (figure $8 \mathrm{~d})$ is expressed as: $I_{\mathrm{pa}}(\mu \mathrm{A})=20 v\left(\mathrm{~V} \mathrm{~s}^{-1}\right)^{1 / 2}-40\left(R^{2}=\right.$ $0.9982), I_{\mathrm{pc}}(\mu \mathrm{A})=20 v\left(\mathrm{~V} \mathrm{~s}^{-1}\right)^{1 / 2}-10\left(R^{2}=0.9986\right)$, for $\mathrm{rGO}$ and $I_{\mathrm{pa}}(\mu \mathrm{A})=4 v\left(\mathrm{~V} \mathrm{~s}^{-1}\right)^{1 / 2}-9\left(R^{2}=0.9676\right), I_{\mathrm{pc}}$ $(\mu \mathrm{A})=5 v\left(\mathrm{~V} \mathrm{~s}^{-1}\right)^{1 / 2}+2\left(R^{2}=0.9885\right)$, for GO. Thus, electrochemical response of rGO is seen to exhibit excellent reversibility, suggesting the easier electron transfer and enhancement in electrocatalytic activity.

To evaluate the conductivity of rGO and GO the electrical resistances of the samples were measured, results show a sharp decrease in resistance of $\mathrm{rGO}(182 \Omega)$ compared 

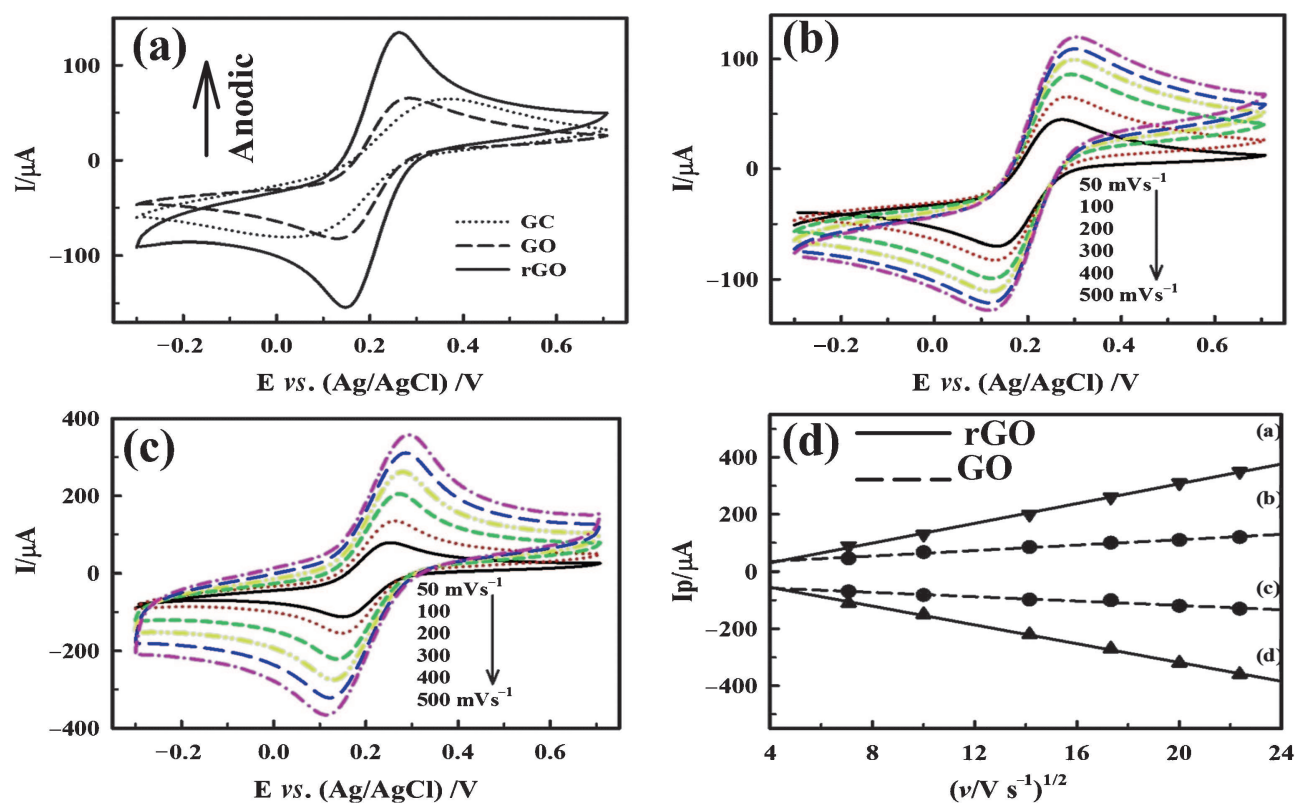

Figure 8. Cyclic voltammograms of samples recorded in $5.0 \mathrm{mM} \mathrm{K}_{3}\left[\mathrm{Fe}(\mathrm{CN})_{6}\right]+1.0 \mathrm{M} \mathrm{KCl}$ solution vs. $\mathrm{Ag} / \mathrm{AgCl}$ reference electrode: (a) bare GC and GC electrode modified with GO and rGO at a scan rate of $100 \mathrm{mV} \mathrm{s}^{-1}$, (b) GO (c) rGO electrode recorded as a function of scan rate and (d) plot of $I_{\mathrm{p}}$ (oxidation and reduction peak) vs. square root of scan rate.

with that of GO $(600 \mathrm{k} \Omega)$. Therefore, the above mentioned analyses clearly reveal that GO is reduced to graphene by $\gamma$-irradiation.

\section{Conclusions}

rGO has been obtained by $\gamma$-irradiation of GO in $1: 1$ waterethanol mixture for a total dose of $11.52 \mathrm{kGy}$ at a relatively low dose rate of $0.24 \mathrm{kGy} \mathrm{h}^{-1}$. The reduction of GO to rGO was evaluated by FTIR, UV-Vis, PL, micro-Raman spectroscopy and XRD analysis and the morphology of products were studied using SEM. The synthesized product exhibits high conductivity and enhanced electrocatalytic activity.

\section{Acknowledgements}

We acknowledge financial supports provided by Department of Chemistry, University of Pune. CNQS, Department of Physics, University of Pune, for XRD, SEM, FTIR facilities, Prof Pavankumar, IISER, Pune, for Raman spectra and Prof Hedayatollah Ghourchian, University of Tehran, are gratefully appreciated for fruitful discussions.

\section{References}

1. Kim K S, Zhao Y, Jang H, Lee S Y, Kim J M, Kim K S, Ahn J H, Kim P, Choi J Y and Hong B H 2009 Nature 457706

2. Balandin A A, Ghosh S, Bao W, Calizo I, Teweldebrhan D, Miao F and Lau C N 2008 Nano Lett. 8902
3. Li D, Mülleri M B, Gilje S, Kaner R B and Wallace G G 2008 Nat. Nanotechnol. 3101

4. Segal M 2009 Nat. Nanotechnol. 4612

5. Jo G, Choe M, Lee S, Park W, Kahng Y H and Lee T 2012 Nanotechnology 23112001

6. Li Q, Guo B, Yu J, Ran J, Zhang B and Yan H 2011 J. Am. Chem. Soc. 13310878

7. Qian W, Hao R, Zhou J, Eastman M, Manhat B A, Sun Q, Goforth A M and Jiao J 2013 Carbon 52595

8. Yang J and Gunasekaran S 2013 Carbon $\mathbf{5 1} 36$

9. Shao Y, Wang J, Wu H, Liu J and Aksay I A 2010 Electroanalysis 221027

10. Liu F, Piao Y, Choi K and Seo T S 2012 Carbon 50123

11. Ponomarenko L A, Schedin F, Katsnelson M I, Yang R, Hill E W, Novoselov K S and Geim A K 2008 Science 320356

12. Geim A K and Novoselov K S 2007 Nat. Mater. 6183

13. Wintterlin J and Bocquet M L 2009 Surf. Sci. 6031841

14. Eizenberg M and Blakely J M 1979 Surf. Sci. 82228

15. Gilje S, Han S, Wang M, Kang K L and Kaner R B 2007 Nano Lett. 73394

16. Gomez-Navarro C, Weitz R T, Bittner A M, Scolari M, Mews A, Burghard M and Kern K 2007 Nano Lett. 73499

17. Schniepp H C, Li J L, McAllister M J, Sai H, Herrera-Alonso M, Adamson D H, Prud'homme R K, Car R, Saville D A and Aksay I A 2006 J. Phys. Chem. B 1108535

18. Niyogi S, Bekyarova E, Itikis M E, McWilliams J L, Hammon M A and Haddon R C 2006 J. Am. Chem. Soc. 1287720

19. Stankovich S, Piner R D, Chen X, Wu N, Nguyen S T and Ruoff R S 2006 J. Mater. Chem. 16155

20. Stankovich S, Dikin D A, Piner R D, Kohlhaas K A, Kleinhammes A, Jia Y, Wu Y, Nguyen S T and Ruoff R S 2007 Carbon 451558 
21. Si Y and Samulski E T 2008 Nano Lett. 81679

22. Wang G, Yang J, Park J, Gou X, Wang B, Liu H and Yao J 2008 J. Phys. Chem. C 128192

23. Henglein A and Meisel D 1998 Langmuir 147392

24. Rao V M, Castano C H, Rojas J and Abdulghani A J 2013 Radiat. Phys. Chem. 8439

25. Rojas J V and Castano C H 2012 Radiat. Phys. Chem. 8116

26. Casaos A A, Puértolas J A, Pascual F J, Hernández-Ferrer J, Castell P, Benito A M, Maser W K and Martínez M T 2014 Appl. Surf. Sci. 301264

27. Safibonaba B, Reyhanib A, Nozad Golikandb A, Mortazavib S Z, Mirershadib S and Ghorannevissa M 2011 Appl. Surf. Sci. 258766

28. Zhang B, Li L, Wang Z, Xie S, Zhang Y, Shen Y, Yu M, Deng B, Huang Q, Fan C and Li J 2012 J. Mater. Chem. 22 7775

29. Zhang Y, Ma H, Zhang Q, Peng J, Li J, Zha M and Yu Z 2012 J. Mater. Chem. 2213064

30. Remita H, Lampre I, Mostafavi M, Balanzat E and Bouffard S 2005 Radiat. Phys. Chem. 72575

31. Krishnamoorthy K, Mohan R and Kim S J 2011 Appl. Phys. Lett. 98244101

32. Xu Sh, Yong L and Wu P 2013 ACS Appl. Mater. Interfaces 5 654

33. Vasu K S, Chakraborty B, Sampath S and Sood A K 2010 Solid State Commun. 1501295

34. Qian W, Chen J, Wei L, Wu L and Chen Q A 2009 Nano 47
35. Alam M S, Rao B S M and Janata E 2003 Radiat. Phys. Chem. 67723

36. Alam M S, Rao B S M and Janata E 2001 Phys. Chem. Chem. Phys. 32622

37. Belloni J, Mostafavi M, Remita H, Marignier J L and Delcourt M O 1998 N. J. Chem. 221239

38. Janata E 2002 Indian Acad. Sci. 114731

39. Guo H, Wang X, Qian Q, Wang F and Xia X 2009 ACS Nano 32653

40. Shang J, Ma L, Li J, Ai W, Yu T and Gurzadyan G G 2012 Sci. Rep. 2792

41. Sheng Y, Tang X, Peng E and Xue J 2013 J. Mater. Chem. B 1512

42. Zhang L, Liang J, Huang Y, Ma Y, Wang Y and Chen Y 2009 Carbon 473365

43. Hun Huh S 2011 Physics and applications of graphene - experiments, Mikhailov S (ed) Thermal reduction of graphene oxide (InTech) ISBN: 978-953-307-217-3

44. Saner S, Okyay F and Yürüm Y 2011 Fuel 902609

45. Sakika B K, Boruah R K and Gogo P K 2007 J. Chem. Sci. 121 103

46. Dong X, Li B, Wei A, Cao X, Chan-Park M B, Zhang H, Li L J, Huang W and Chen P 2011 Carbon 492944

47. Dong X, Xing G, Chan-Park M B, Shi W, Xiao N, Wang J, Yan Q, Sum T C, Huang W and Chen P 2011 Carbon 495071

48. Lin W J, Liao C S, Jhang J H and Tsai Y C 2009 Electrochem. Commun. 112153 